\title{
The fortress, a house with a vision
}

\author{
B. D'hoore ${ }^{1} \&$ P. Quataert ${ }^{2}$ \\ ${ }^{1}$ Architectgroup D'hoore, Belgium \\ ${ }^{2}$ Regional Landscape Meetjesland Foundation, Belgium
}

\begin{abstract}
In 2004, the Regional Landscape Meetjesland Foundation began to work on a cultural landscape development plan for the hamlet of Strobrugge (with its 100 inhabitants), in collaboration with the different stakeholders. Strobrugge is a green enclave in an urbanised rural landscape and is situated at the fringe of the town of Maldegem (20,000 inhabitants), between two historical canals (the Leopold Canal and the Schipdonk Canal, both dug in the 19th century) and the Lieve, a relic of a medieval canal. One of the keys in the social and cultural revalorisation of the hamlet is the construction of a meeting place (building). The name of the building is 'The Fortress'. It refers to a fortress built in Strobrugge in the $19^{\text {th }}$ century near the border with the Netherlands. The Fortress aims to be a meeting and knowledge centre in the areas of ecology (focusing on the importance of water). We hope it will help to put architecture on the agenda as one of the key elements in sustainable regional development, as architecture has both a socio-cultural and a socio-economic and environmental role to play. The first drafts were drawn in 2006. They have now been submitted for investigation to the authorities, inhabitants and other stakeholders. The architect's work is based on a multi- and even interdisciplinary approach: ecology, energy, history, society, landscape, culture, politics, etc. These are all elements that have been taken into account during the process of planning/drawing.

Keywords: sustainable regional development, cultural ecology, stakeholders, strategic approach, interdisciplinarity, vision is important, cultural landscape, sense of a place.
\end{abstract}

\section{Introduction}

We all know that the built environment (architecture) is a part of the landscape (urban or rural) and that it determines to great extent the identity and the quality of a region. Landscape quality is important for the quality of life and for the 
development of a region, a municipality, a neighbourhood, a street, etc. Architecture, in its broad sense, contributes so to the sustainable development of a region. "Regional development" is a concept used in European and national policies and refers to management processes which aim to develop a region (urban or rural areas). With this in view, the idea was raised in a tiny hamlet in the small rural area of Meetjesland in Flanders/Belgium to build a cultural centre, called 'The Fortress'. We hope that the Fortress will contribute to the socio-cultural and environmental development of the hamlet. The Fortress is considered to be an "experiment" on sustainable architecture. What do we mean with "sustainable" architecture? We refer to the concept of "sustainable development".

\section{Sustainable development and cultural ecology}

According to Michael Redclift [1] the term sustainable development can be interpreted in many different ways, depending on the approach and emphasis, the context of the discussion, and the audience present

We refer especially to the ideas of Bryan Farrell [2]. He reflects in an interdisciplinary, holistic and positive way on the meaning of sustainable development. He states that in the development system there are three critically important and interdependent subsystems : economy, environment, and culture (including society). This is the so called development triangle. "Taken together, the expanded system largely equates in practical terms with the total environment, the total ecosystem, or more precisely the human environment, as an operational system. For a sustainable development, no component may be more important than any other. Conversely, environmental systems cannot realistically exist in an operational vacuum but must co-exist with judicious economic development and address relevant needs and aspirations of society." Farrell believes in a socio-cultural approach: "To think narrowly of the human world order in terms such as the "natural environment perturbed by human agencies' omits so much, is unrealistic and artificial, destroys an integrated approach, and by its restrictiveness all but denies sustainability in its non-fundamentalist new sense." We all know that ecology is a biological study of the relationship of plants and animals to each other and to their environment. Farrell's point of departure is the notion of "cultural ecology". This concerns the study of the relationship of human beings to each other and to their environment. When we apply this cultural approach of Farrell to architecture we can state that the relationship of communities, tourists, visitors, managers, developers, architects, policymakers, ... to each other, and especially to their environment, is the substance of ecological architecture and, certainly, sustainable development.

\section{Landscape and architecture as part of the development triangle}

The built environment determines the landscape for a big part in Flanders and shapes it. Landscapes have a lot of different values: ecological, historical, 
economical, cultural, spatial, etc. The mixture depends on the context and gives a special character to the place. To destroy one of the values is often a deterioration of the quality of the landscape and its character.

It is important to understand the meaning of landscape because it is often subject of misunderstanding. Technically spoken a landscape is the result of the interaction of the biotic (fauna and flora), the abiotic (air, water, climate, ...) and human elements. A cultural landscape is the result of nature and culture. To Kelly Shannon of the University of Leuven department Architecture, Urbanism and Planning [3], there is a shift from landscape as a negotiated condition between "natural" and "artificial" towards landscape as a richer term, embracing urbanism, infrastructure, strategic planning, architecture and innovative ideas. Landscape discourse has shifted from landscape-as-picture to landscape-asprocess. This new approach means that landscape (and so architecture) has an important role to play in the socio-economic and socio-cultural development of a place.

\section{Regional Landscape: a forum with a vision and a unique rural area}

\subsection{Regional Landscape Meetjesland}

In Flanders, urbanisation and the EU agricultural policy have transformed the countryside both functionally and morphologically. In Flanders there is since the beginning of the nineties a regional development policy based on the idea of "sustainability". A lot of experiments have been launched since then. One of them was the creation of "Regional Landscapes" in rural areas. The meaning of a Regional Landscape is double. On the one hand a Regional Landscape is a distinctive geographical rural area (at least $30.000 \mathrm{ha}$ ) with a lot of landscape qualities or potentials to develop them. On the other hand a Regional Landscape is a regional platform or forum in which public and private stakeholders of the area are cooperating. The objective is to create more awareness and responsibility in the region for nature and culture and to use them as motors for regional development.

In Flanders there are ten rural areas recognised by the Flemish Government as "Regional Landscape". One of the areas is "Meetjesland". The area is a rural area (13 municipalities and 162.000 inhabitants) between two major cities of Ghent (230.000 inhabitants) and Bruges (120.000 inhabitants). The primary characteristic that defines this region is that it is dominated by open space for agricultural purposes. However, one is never far from an urban settlement of some size and urbanisation processes are visible. Because of this, a curious relationship is established between urban and rural identities, and neither is ever entirely free of the other. Meetjesland, is characterized by different landscapetypes. Originally, the Meetjesland was a sandy area. From the end of the $12^{\text {th }}$ century until the $17^{\text {th }}$ century, a succession of floods occurred from the Scheldt River. The Northern part of the Meetjesland was, thereby, covered with clayey sediments, and a contrast developed between an old landscape (the sandy soils in 
the South) and a young one, called the polders (the clayey soils in the North). The character of the villages, the houses, the farms, ... has been influenced by the features of the different landscape-types.

\subsection{The development strategy for Meetjesland}

The Foundation Regional Landscape Meetjesland made part of a think tank for the region on sustainable development. This group of people made in 2005 and 2006 the framework for a vision for the region. It is a description in which direction the region of Meetjesland must evaluate in the coming 20 years. All the stakeholders of the area have been involved in one way or another. Meetjesland wants to join the knowledge society but respects at the same time its rural identity (tradition). The quality of the cultural landscape and the open space are considered as very important values. This vision is not a detail. All the actions in the area must help to realise the vision. Architecture is one of them, sustainable architecture.

\section{Development plan for Strobrugge}

The case "Strobrugge" is an example of a small development project which fits in the described regional vision. The aim is to develop Strobrugge by valorisation of its landscape features (natural and cultural). The Regional Landscape Forum has made a kind of Masterplan for the hamlet. One of the actions in the plan is "the Fortress", a new cultural centre.

\subsection{A small hamlet with a rich history and water as key actor}

Strobrugge is the northern quarter of Maldegem (20,000 inhabitants), situated near the place where the provinces of East Flanders, West Flanders and Zeeland (Netherlands) meet. The hamlet of Strobrugge has about 80 inhabitants. The local landscape here is part of the flat and sandy Meetjesland, whereas to the north of Strobrugge, one will find the wet polder landscape with marine clayey soils. Strobrugge's position is quite exceptional, as it is situated on a peninsula that is spatially bounded by the Leopold Canal and the Schipdonk Canal. As such, the area was determined by attempts by men to use the waterlogged land as farmland. In spite of major and systematic reclamation works from the 13th century on, most of the land remained difficult to farm because of flooding until the middle of the 18th century.

After Belgian independence, when the Dutch closed all the drainage brooks, drainage over Dutch territory became impossible. This was a catastrophe for the northern parts of East and West Flanders. In this context the Leopold Canal was constructed. More or less at the same time, the Schipdonk Canal was built. The Schipdonk Canal linked the Leie with the North Sea. These two new canals converged in Strobrugge. 


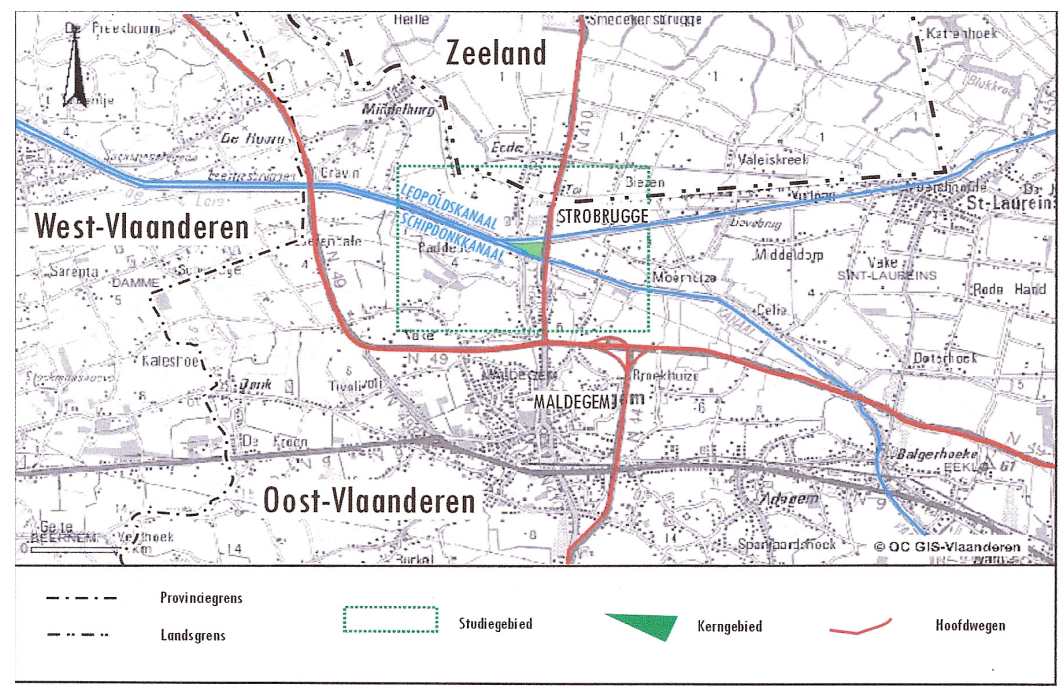

Figure 1: Strobrugge.

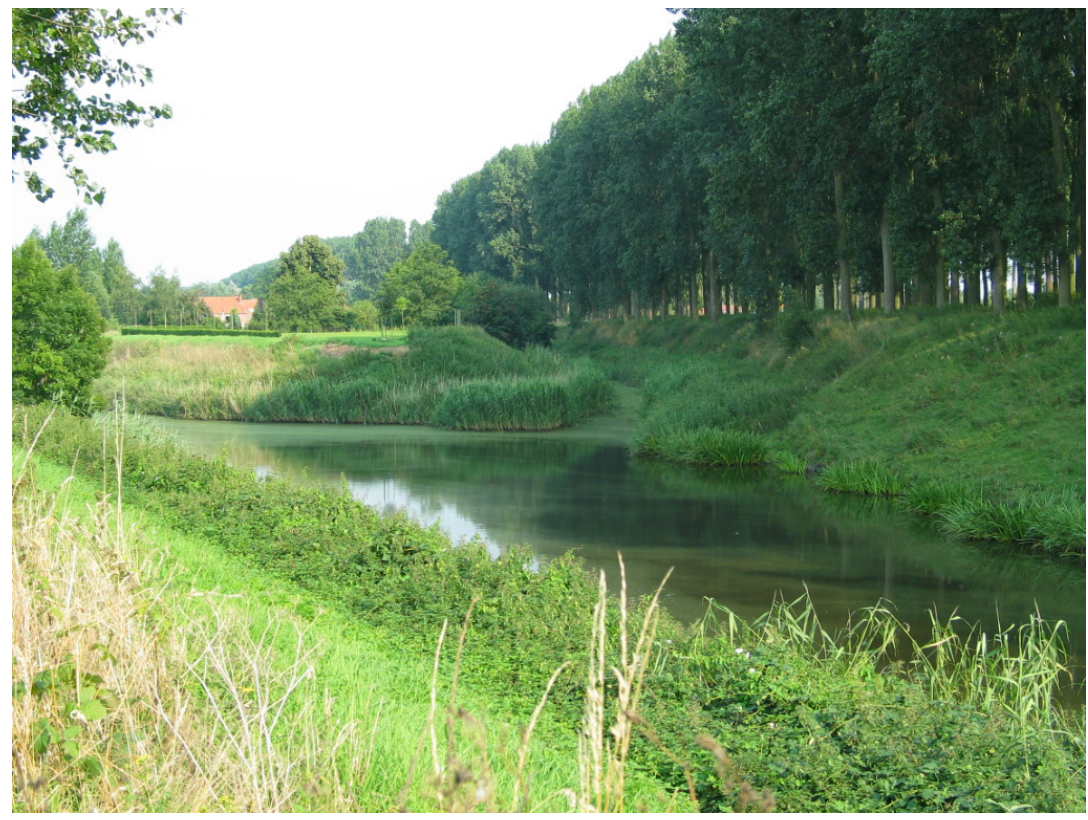

Figure 2: Leopold Canal in Strobrugge.

Strobrugge was a strategic important place near the border with Holland. The hamlet was indeed often the scene of battle for the border wars during Belgium's 
fight for independence and it remained in the line of defence near the border with the Netherlands. In September 1831 the construction of a fortress began. The fortress was meant to defend the border. It consisted of two military buildings surrounded by two earthen fortifications. The fortress could hold 200 men. Strobrugge's fortress continued to exist until 1841, when its destruction was required for the digging of the Leopold Canal.

After the independence of Belgium, Strobrugge was a boundary place with a customs house. From the middle of the 19th century until the end of the 1970s, there was a lot of coming and going in Strobrugge. And because of the customs house and the interchange tram stop, almost everybody halted here. Strobrugge boasted many bars at that time. As the customs disappeared, so did the hustle and bustle of olden days. Since 1990 the hamlet did not have any bars or shops anymore, and therefore the hamlet could not avail oneself of any public space

\subsection{Strobrugge: from vivid to desolate? A need for development}

Today is Strobrugge an isolated place. In the seventies of the previous century, the low bridges were replaced by new and higher ones, and the regional road between Maldegem and Aardenburg was diverted high above the town. This turned Strobrugge into an island with only one access road. The only remaining buildings offer housing to about 50 families. And the central new area, Konduit, looks somewhat like a banal allotment. There is no public meeting place at all and the hamlet looks rather desolate.

The small remaining architectural heritage of engineering works (to manage the water level) and bridges have become dilapidated and run-down. The relics of war, such as blockhouses and emergency houses, have not only fallen into decay but have turned into illegal rubbish tips. And although there are still many cultural and scenic values, Strobrugge makes a somewhat cluttered impression.

\subsection{Masterplanning: leader approach and cultural ecology of Farrell}

Masterplanning can be realised in different ways. The Foundation Regional Landscape Meetjesland is using the method developed by Leader and the cultural ecology approach of Farrell. Leader (Liaisons entre Actions pour le Développement de l'Economie Rurale) is a European Network of Rural areas on the theme of Rural Economic development. The bottom up approach is of high value. It is important to involve all the stakeholders and to let them dream about the future. Communication is the challenge in the whole process.

A first big step was in July 2006. The Foundation and the Municipality of Maldegem organised a information session on a Saturday morning for the inhabitants of the hamlet. In order to lay bare these foundations, the hamlet's socio-economic, socio-cultural and landscape assets needed to be described and analysed. When the study was finalised, the results were presented to more than 100 people in a big barn situated in the hamlet. This event, which aroused a lot of interest and generated many reactions, was paired with a public opinion poll about how the inhabitants saw the future of 'their' hamlet. 

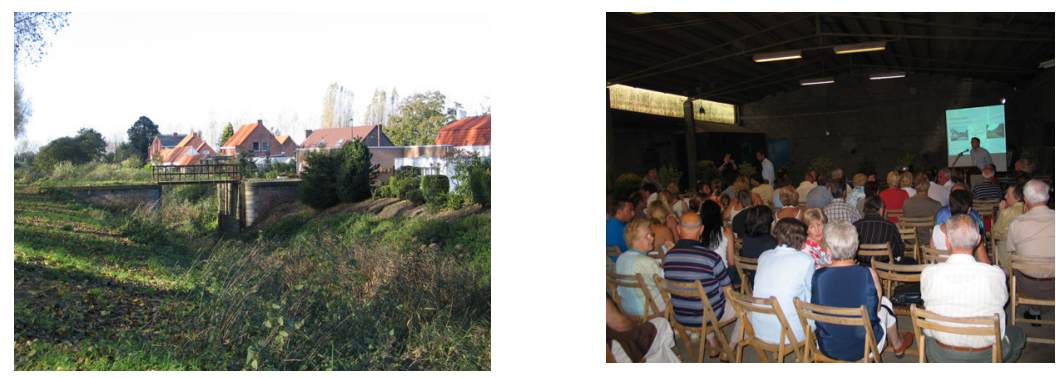

Figure 3: View on the canal "Lieve" and meeting with the inhabitants in July 2006.

\subsection{A vision for Strobrugge as an inspiring guide for action}

The following vision emerged : "We, the inhabitants of Strobrugge, take care of the identity of the place and aim at a sustainable development. It is in the first place a nice area to live and we want to keep it like that. The quietness, the historical background and the cultural landscape values are real assets. We want to valorise these assets and share them with our visitors."

A lot of actions in the future are possible as long as they respect and understand the sense of the place and the feelings of the inhabitants. The analyses and the vision are really important because they serve as a guide for action. Possible actions can compromise the restoration of war relicts, locks, public footpaths, old houses, authentic natural elements of the old canal of the Lieve, etc. The "cluttering" can be stopped and a more beautiful hamlet will appear. One of the landowners on the site wants to create a kind of meeting place for the inhabitants and for visitors outside. It is important to perform better on mobility : a better access for hikers and bikers, the creation of a parking place outside the hamlet, the reorganisation of the regional road, etc.

\section{The fortress}

\subsection{The fortress: a house with a mission}

It is clear that the fortress must help to revitalise on a socio-cultural level the hamlet of Strobrugge and that it has to take care of the social and environmental carrying capacity of the place. It was important to formulate a clear vision for the new centre. The Fortress wants to be a knowledge and cultural centre on ecology with focus on water.

\subsection{The first plans of the fortress:}

For the architect it was very important to feel the sense of the place Strobrugge, to get in touch with the overall vision for Strobrugge, to understand the vision for the Fortress and the interdependence of all that. All this was crucial during the drawing process. 

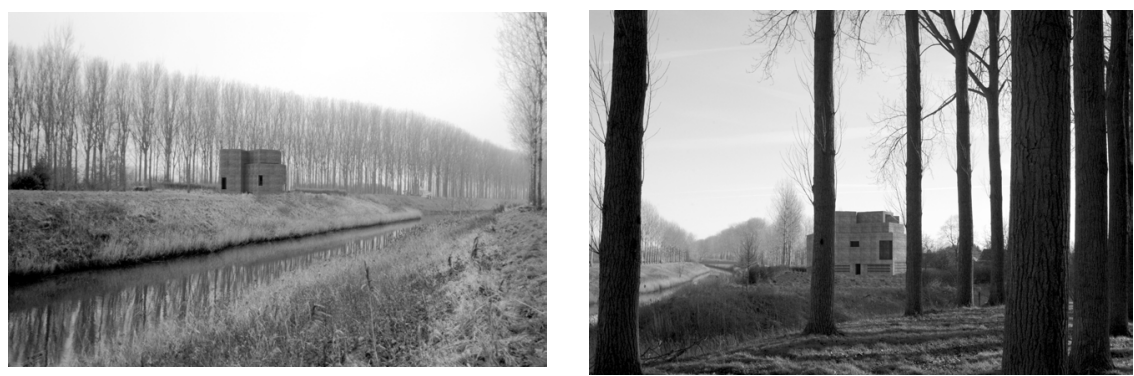

Figure 4: "The Fortress" simulation in three dimensions front and back.

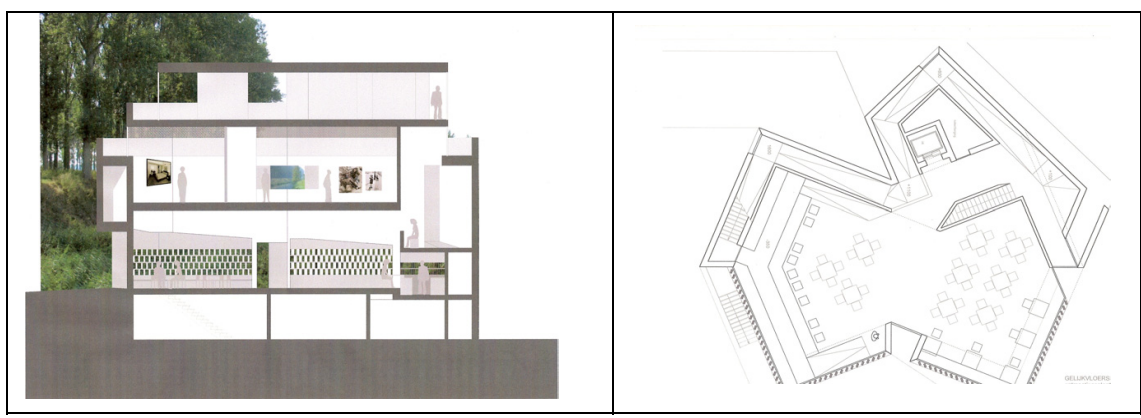

Figure 5: The different floors: cross-section (left) and the ground floor.

In the notebook of the architect we read the following reflections: "The building will be situated in the open space near the 'beak' triangle. The building site is surrounded by water. Because of the exceptional landscape assets of the place and the historical tensions that prevail, the choice has been made to derive the new building's typology from a fortress. Just like the former fortress, the meeting place will be a closed entity. As all of the landscape's aspects are wonderful and interesting, it was suggested that a separate inner and outer environmental experience be created. Thanks to the closeness of the building, the landscape can be integrated in a more surprising manner in the inner space. The capricious forms and shapes of the building fit in well with the landscape and with the inclined plains of the area.

By way of an inclining track, one gradually arrives at the canal level, where the site becomes visible. This is where the building's entrance will be situated. The walk can be continued inside the building, where access can be gained to the higher levels. Every now and then, the staggering trail, which is typical for an architectural design with a strategic mission, reveals some unexpected views of the landscape. The way in which these views are visible from within the building furthermore adds to the extraordinary light inside. Indeed, as the apertures are situated at the corners of the building, the light mysteriously drops in from behind a corner, which generates 
somewhat of an intimate atmosphere. Just like in a real fortress, the visitor gets the chance to make a circuit on the upper floor. This is the 'covered path'. The circuit is situated outside and offers an 'all round' view. This is where the walk ends.

The walk inside forms the key element of a visit to the Fortress. The track encircles the rooms, which gives them an enclosed character and draws the visitor's attention to what is happening within. The ground floor comprises a meeting place, in which the walls only offer a fragmented view of the landscape. The multi-purpose room on the first floor is a closed room, with light coming in through the upper windows. The top floor accounts for the guest rooms. From here, visitors get a good overview of the whole site. They actually look across the 'covered path'. The meeting function of the building is meant to pull the inhabitants away from their isolated position. It should contribute to the establishment of a community feeling. It has been important to create a building that can do something memorable to its visitors. Visiting the Fortress should be a special experience, an event that adds value to the entire site.

The typology that has been used and that was derived from the former fortress conjures up various associations and memories. It refers to history, and to the special nature of this place. The past is brought back to the surface. In this way, the site will not only display but also keep hold of its significance."

\subsection{Challenges}

It is important that the new building helps to implement the vision for Strobrugge. Obviously, it is of utter importance that the building does not cause any nuisance whatsoever to the small community and its natural environment. That is why it has been essential from the very beginning that partners of various disciplines be involved in the project. This allows for adjustments based on their points of view whenever necessary. On the contrary the Fortress must even help to develop the hamlet in a socio-cultural and environmental way. It is a real challenge to use sustainable resource management techniques for energy reduction, water treatment, etc. The art for the architect, the developers and the Foundation Regional Landscape Meetjesland is to integrate all that. The whole is more than the separate parts and the approach is interdisciplinary. Energy reduction is important but we have consciously chosen not to build the Centre with the Passifhaus methodology because other important elements (like history) do, in the case of a full Passifhouse, not get a chance to be fulfilled.

\section{Conclusions}

Farrell's vision on sustainability and the experiment of the Foundation Regional Landscape with the Fortress give us some principles to obtain ecological or sustainable architecture.

The study of the socio-economic, socio-cultural and landscape assets from a specific human environment makes the different facets clear, closely related to the identity who makes from a place that specific place. 
It is this 'sustainable' context that we intrinsically have to work in and with. The site in itself is inspiring and fosters solutions that give way to new relationships in the further development.

Sustainable development and architecture is a continuous process that starts out from the broadest context possible to gradually zoom in afterwards. In the specific development of the project you may never forget the bigger context. This approach allows for very specific and appropriate interventions, which are closely tuned to the spot.

Sustainable architecture takes in account the character of the total human environment (economy, society, landscape) and must even have a positive effect on this total environment. So it has a socio-economic, a socio-cultural and ecological mission.

Sustainable development will be obtained by sticking to a common vision, that will not necessarily be the one and only truth. There is not just one solution. In this never ending process, in this multi- and interdisciplinary approach, the Foundation Regional Landscape Meetjesland has the role as co-ordinator and producer.

\section{References}

[1] Redclift, M., The meaning of sustainable development, Geoforum, Vol.23, No. Z, pp. 395-403, 1992.

[2] Farrell, B., Tourism as an Element in Sustainable Development: Hana, Maui (chapter 6). Tourism Alternatives: potentials and problems in the development of tourism, ed. Smith, V.L. \& Eadington, W.R., University of Pennsylvania Press, pp. 115-134, 1992.

[3] Shannon, K., Searching and restoring landscape quality, Preparation of workshop landscape quality in the conference Rurality near the city, Leuven, 8 Feb. 2007. 